\title{
Engines of learning? Policy instruments, cities and climate governance
}

\author{
Ekaterina Domorenok ${ }^{1}$ (D) . Anthony R. Zito ${ }^{2}$ (D)
}

Accepted: 22 June 2021 / Published online: 8 July 2021

(c) The Author(s) 2021

\begin{abstract}
This contribution investigates how combinations of instruments, often called policy mixes, enhance policy learning processes at different levels. It analyzes the European Union's (EU) Covenant of Mayors (CoM) that is underpinned by a set of learning instruments, to promote local action for sustainable energy and climate. The piece offers an original framework to explore whether and how the Covenant enhances learning at the level of European institutions and among local governments. Drawing on an extensive documentary review and elite interviews in four countries (Germany, Italy, Poland and the UK), the analysis shows that the CoM instrument mix has enhanced certain elements of learning within the actors leading the Covenant as well as many of the local governments within and outside the EU, but only if certain conditions operate, such as political leadership, individual motivation and knowledge and regional coordination mechanisms.
\end{abstract}

Keywords Policy learning · European Union · Cities · Policy change $\cdot$ Climate change · Covenant of Mayors

\section{Introduction}

Over the last decade, an increasing number of studies have investigated how different instruments can enhance policy learning in multi-level settings, especially in the global climate governance context (Jordan et al., 2018). The European Union's (EU) experience has attracted particular attention. Network governance architectures, underpinned by coordination and learning mechanisms which target sub-state authorities and non-state actors, have diffused across EU policy sectors, with cities acting as important protagonists (Smeds \& Acuto, 2018). The EU Commission Directorates General (DGs) and Executive

Ekaterina Domorenok

ekaterina.domorenok@unipd.it

Anthony R. Zito

anthony.zito@newcastle.ac.uk

1 Department of Political Science, Law and International Studies, University of Padova, Padua, Italy

2 The School of Geography, Politics and Sociology, Newcastle University, Newcastle upon Tyne, UK 
Agencies are often directly involved in these networks, providing coordination and/or support functions.

These trends raise questions about whether, how and under which conditions specific instruments actually encourage learning processes and the implications for the EU (Wolfram et al. 2019, Zito \& Schout, 2009). Efforts to appraise systematically the effectiveness of individual instruments, or their combinations within policy mixes, for supporting learning across different policymaking levels are scarce (Radaelli, 2008).

This contribution addresses these gaps by assessing the learning effects of an important EU instrument, the Covenant of Mayors (CoM), and investigating whether and how this program's mix of learning instruments influences a wider climate policy and instrumental context (Howlett \& Rayner, 2013). Specifically, our research addresses the following questions: How and to what extent can a mix of specific policy devices encourage the learning process at different governance levels? Can the same instrument mix generate more than one type of learning? Under what conditions do actors learn and what prevents learning?

The CoM is a particularly promising case: it represents a mix of policy instruments designed to produce a coherent, positive impact on local climate governance (Howlett \& Rayner, 2007). The EU Commission launched the CoM in 2008, with the objective of supporting local sustainable energy and climate action. The CoM has activated a mix of learning instruments (i.e., policy guidance, templates, training, benchmarking tools, collaborative networks, etc.), aiming to encourage local authorities to align to common policy goals, adjust their local policy instruments to shared methods and metrics, and learn from each other by exchanging good practices.

Our original contribution is twofold. We construct a novel theoretical approach for assessing how a policy mix of instruments support three different dimensions of reflexive learning (i.e., a range of actors deliberating and changing their policies voluntarily and over time-Dunlop \& Radaelli, 2018). The framework allows scholars to isolate how a set of instruments can target actors operating across a complex policy sector and induce different kinds of learning. Secondly, we assess whether this CoM program has enhanced different types of learning among EU actors. This approach also provides analytical tools for understanding how instrument design, selection and application bridge and influence actors' political motivations and the policy processes.

Our empirical findings rely on an extensive overview of EU documents, secondary data analysis and 18 semi-structured interviews of senior policy officers charged with the CoM activities in four EU countries, which show contrasting climate policy approaches. Germany and the UK have been leaders of aspects of climate policy compared to Italy (often viewed as a more reactive, laggard country) and Poland, noted for its opposition to particular EU climate measures (Wurzel et al., 2019).

The next section presents the theoretical debate and argument. Section Three introduces our research design, while Section Four details the method. Sections Five through Seven present our empirical findings. The closing section discusses our conclusions.

\section{Theoretical background and conceptual framework}

European integration studies have investigated how new governance modes, underpinned by learning mechanisms, have progressively spread across EU public policies (Zito \& Schout, 2009). In these new modes, no single actor has the capacity to impose solutions; the solutions rely on pluralist dialog expected to induce reflexive learning and consequently 
policy change (Sabel and Zeitlin 2008). Most of the empirical research has focused on the EU Open Method of Coordination (Radaelli, 2008); few efforts systematically assess the relevance of other individual instruments and mixes.

Following Dunlop and Radaelli (2019), we conceive learning as a deliberate process to adjust the organizational strategies, policy goals and/or policy tools/techniques, responding to past experience and new policy-relevant knowledge. We focus on reflexive learning associated with: the operationalization of a set of instruments (policy mix) underpinned by the logic of force-free deliberation; the absence of pre-defined teachers; and changing participants over time (Dunlop \& Radaelli, 2013). This learning involves a wide range of social actors in an iterative process aimed at handling policy problems for which no obvious solution exists. The instrument mix's main task is to facilitate agreement on common objectives and encourage communication throughout the network so that the participating local actors can find and validate a solution. The main assumption is that different forms of expertise and specific instruments may encourage learning, generating consensus on appropriate solutions. Decision-makers learn about 'how' rather than simply 'what' to learn, but this does not occur under all conditions (Dunlop \& Radaelli, 2018).

The policy learning literature suggests various conditions that may promote learning; a successful policy instrument mix should generate these conditions. Radaelli (2020, p. 233) notes the importance of socialization and the direct involvement of the various interested actors in producing learning, of favorable leadership at key policy junctions and of having both the delegates and the supporting bodies mutually own the policy/learning process. Benz and Fürst (2002) emphasize the importance of network interactions within subnational government, especially structures that garner heterogeneous actor input. They argue that learning also occurs when regions successfully combine competitive and co-operative dynamics (in pursuing knowledge and best practice) in a system emphasizing trust and loosely coupled relationships that enable institutions to learn and adjust voluntarily. Other scholars stress the importance of appropriate policy evaluation and testing to assess what works in a policy effort (Sanderson, 2002; Schoenefeld \& Jordan, 2019). The relationship between governance and learning also appears important; under certain conditions reflexive governance settings underpinned by polyarchic structures, iterative goal-setting and coproduction of knowledge can generate learning (Dunlop, 2015).

Building on the policy learning scholarship (Hall 1993; Dunlop \& Radaelli, 2013, 2019), we unpack the learning mechanisms embedded in the CoM. Unlike most existing studies that have focused on specific learning (i.e., policy, organizational, political) types following either top-down or bottom-up directions, our comprehensive analytical framework uncovers whether and how specific policy instruments have enabled learning across multiple governance levels.

Hall (1993) provides an important conceptual foundation. By asserting the importance of changes in policy paradigms, programs and instruments, Hall articulates that important policy change can happen at the macro- (substantial changes in paradigms-e.g., Keynesianism to Neoliberalism), the meso- (changes in the core objectives and programs that govern a policy sector) and the micro- (changes in tools to steer societal actors) levels. We are particularly interested in how the CoM program (meso) policy mix shapes two sets of learning dynamics: (1) microchanges in local policy instruments (such as plans, monitoring schemes and policymaking procedures); (2) meso- and microreorganization of relationships between levels of government within and across countries.

Hall places the explanatory weight for major policy change with the (macro) paradigmatic learning dynamics, building on the social learning literature (Heclo, 1974). Nevertheless, instrumental change can trigger major policy change. Howlett and Cashore 
(2009) underline this point, both in terms of the need to complicate the levels and processes that Hall articulates and to identify the importance of other mechanisms. Individual policy instruments, or in the CoM's case a mix of instruments, are relevant for learning, and they may have an independent or certainly intervening impact on political and policy learning. The EU Emissions Trading System is one such instrument generating global political and policy implications (Ranson \& Stavins, 2016); instruments can have this impact even more so at the meso- and microlocal levels.

\section{Research design}

Our analytical framework focuses on two sets of dimensions. The first dimension comes from Radaelli (2008), asking who is instigating learning and who is the target of learning? First, 'learning at the top' depicts learning that originates, circulates and seeks to influence actors at the top of the multi-level process and hence to shape and calibrate the instruments (this study focuses on European Commission decision-making). 'Topdown' describes learning originating at the top but directed at steering local government actors. 'Bottom level' describes learning originating and circulating at the lower municipal level (in terms of our focus). It may also entail a learning dynamic moving upward to the national, EU and perhaps even global levels through learning feedback via the interorganizational networks within each member state and through the transnational networks involving CoM members.

The second dimension isolates the different learning types that the instrument mix may generate (Moyson et al., 2017). Our framework leaves out the possibilities of radical paradigm shifts in public policy (i.e., what Hall labelled social learning). Our expectation is that municipal actors that embrace $\mathrm{CoM}$ will have experienced the social learning (in acknowledging the political and policy necessity of climate crisis responses) in becoming CoM members, a step that pre-dates our analysis and therefore our focus. Consequently, social learning is implicit in our framework; the following learning types are more likely to reflect single-loop learning (i.e., the learning does not question fundamental organizational values and activities-Argyris, 1976, p. 367).

In assessing the CoM instrument mix's impact on policy learning, note that this mix will influence policy by shaping substantive delivery of outputs but also the policy process at the level of substantive and procedural instruments (Howlett \& Rayner, 2007). We expect both dynamics to operate in the CoM and organize our framework accordingly. In the policy learning type, learning processes cover the overarching strategies and policy aims, including both organizations seeking to understand the perspectives and interests of other actors operating in the same political context (May, 1992) and the organizations' propensity to assess and improve their overall policy performance (Hildén, 2011). The instrumental type implies learning about policy instruments, their potential roles and design in order to fulfill policy aims. Organizational learning involves the local government and other institutions altering their core tasks and internal processes, relations and roles, to respond to newly gained ideas and information (Simon, 1961).

Using our dimensions, we generate an analytical matrix that spells out analytically and measures empirically the process of reflexive learning that CoM can generate. Table 1 presents this matrix, framing how the two dimensions intersect. 


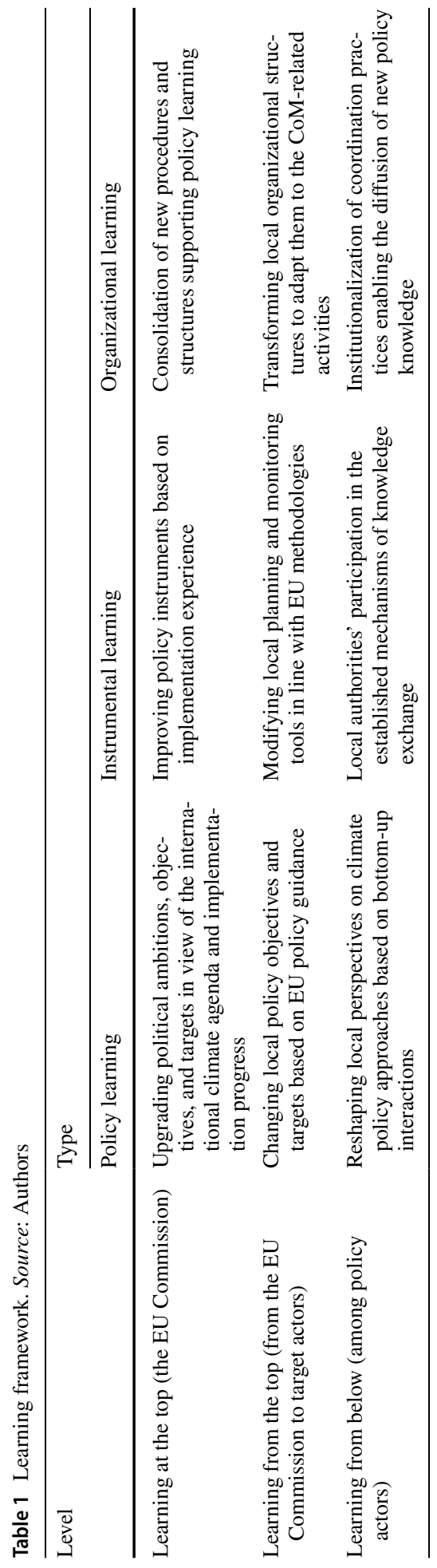


By analyzing the CoM learning instruments, we answer the following questions:

- How and to what extent can a mix of specific policy devices encourage the learning process at different levels?

- Can the same instrument mix generate more than one learning type?

- Why do actors learn and what prevents them from learning?

CoM offers a promising case study to answer these questions. This program activates multiple learning instruments working as a policy mix; its objective is to encourage local authorities to build sustainable energy and climate policies based on EU objectives and targets. This mix includes (1) regulatory and methodological guidance based on EU goals, (2) a benchmarking instrument, (3) different information sources, (4) informational and training events and 5) collaborative networks. Although the EU Commission and the CoM coordinating bodies design the overall policy guidance and offer support for each activity, local authorities enjoy wide discretion in how they adapt the CoM framework, select the instruments and use these instruments.

In terms of policy learning from the top, the CoM signatories are expected to adjust and periodically revise their climate policies and targets based on the evolving CoM objectives. The European Commission's Joint Research Centre (JRC) prepares a common template and methodological guidelines to guide signatories in their instrument learning when the signatories develop an emissions inventory, draw sustainable energy/climate action plans ( $\mathrm{SE}(\mathrm{C}) \mathrm{APs}$ ) and perform periodic monitoring of the progress toward meeting the CoM targets. The JRC validates each plan after checking its fulfillment of the minimum requirements and data coherence/completeness. The organizational and procedural learning from the top is associated with an inclusive decision-making style that the CoM promotes by requiring its signatories to enhance cross-sectoral coordination within their administrations and establish extensive local partnerships involving private actors and local communities in the definition and implementation of SE(C)APs activities.

The CoM bottom-up learning instruments include a benchmarking tool operating through the program website, which creates a pool of practical knowledge on successful local experiences and a multilevel system of territorial coordinators (Regions, Provinces) and supporters (specialized agencies). The latter assist the CoM activities at the local level, sharing their own knowledge and resources. The program website contains copious information packages to provide signatories with thematic and methodological insights on building, implementing and improving local climate policies. The Covenant of Mayors Office (CoMO) promotes training and information events to enhance knowledge production and exchange among CoM signatories.

Within both the dimensions (learning 'from the top' and 'from the bottom'), spontaneous activation of signatories and their supporting bodies based on the CoM policy should drive the learning process. We expect that a policy instruments mix will trigger learning if some of the following conditions operate. Learning is more likely if the instrument mix encourages: socialization by the CoM members (Radaelli, 2020); participation including as many stakeholders as possible in the co-production of knowledge (Ibid); processes that exploit the membership's heterogeneity to incorporate diverse perspectives and experiences (Benz \& Fürst, 2002); the building of trust among the CoM members and supporting CoM bodies (Ibid); cooperative and competitive incentives that induce CoM members to improve their performance (Ibid); a well-resourced and extensive policy mix that triggers systematic reflection by all CoM members and supporting bodies (Sanderson, 2002); and finally a stable institutional capacity that retains knowledge and expertise (Dunlop, 2015). 
We suggest that the CoM mix's learning effect is higher the more these CoM instruments increase the signatories' awareness and knowledge about new climate policy challenges and solutions, the more intensely the CoM cooperative and competitive incentives induce signatories to develop or upgrade local policies and instruments in line with EU policy guidance, and the more constructively the signatories respond to the CoM trigger of systematic monitoring and benchmarking. Enabling interactions between the CoM signatories and its supporting bodies and enhancing the involvement of as many stakeholders as possible in co-producing knowledge, allow the program to harness the heterogeneity of participants and incorporate diverse perspectives and experiences (Proposition One).

The 'smart mixes' literature (which argues that particular combinations of instruments can enhance policy effectiveness) offers additional important learning conditions: avoidance of creating too many instruments that negatively complicate the policy process and policy mix, instrument types and settings that work (rather than conflict) with the other instruments in the mix, adequate resourcing for each instrument and adaptability in the instrument design (van Erp, 2019a, 2019b). These conditions ensure policy coherence (the ability for the policy elements to co-exist with each other in a logical manner) and policy congruence (instruments working in the same direction) (Howlett \& Rayner, 2013). The greater degree that these positive conditions operate in the CoM mix (and the degree the reverse conditions are minimized), the more effective CoM will be in enhancing all three learning types within the CoM process (Proposition Two).

Given our argument that learning processes develop in multiple directions, we anticipate potential learning at the top, involving the CoM coordinating bodies (the EU Commission, the CoMO and the JRC). The learning impact of the CoM is higher the more pro-active its coordinating bodies are in performing periodic assessment, revision and improvement of the program (Schoenefeld \& Jordan, 2019), reflecting both the evolving international agenda and the evaluation of CoM implementation results (Proposition Three).

\section{Method}

This research mainly relies on qualitative methods (Gerring, 2017), combining the content analysis of desk sources and semi-structured interviews, in order to provide a sufficiently comprehensive understanding of the CoM learning impact over ten years of activity.

Building on process tracing methodological insights (Collier, 2011), we have conducted an extensive documentary analysis, including thematic reports, case studies and fact sheets covering CoM activities since 2008. We scrutinized these documents to obtain a fine-grained description of the CoM's workings, discerning the learning dynamics that our research addresses through a range of comparable observations concerning the evolution and usage of CoM learning tools.

We have also used the secondary data presented in a number of the CoM's enquires to answer more specific questions concerning signatories' knowledge needs, their motivation to participate in the CoM and their perceptions about the program's relevance for acquiring new knowledge and expertise. These reports cover a considerable sample of CoM signatories and are available online (COM, 2016, CoM, 2017; van der Veen et al., 2013). We have also systematically observed how the CoM online learning tools, including templates, manuals, library and datasets evolved during the period 2017-2019 in order to understand if a learning process at the top has occurred. 
We conducted 18 in-depth, semi-structured interviews (see "Appendix 1") to obtain signatories' views on the CoM's relevance in the four countries. Our interviews were conducted in English and targeted local senior policy officers charged with the CoM-related activities. We sent invitations to all CoM signatories in Germany (63), Poland (39) and the UK (34) as of 2017; for Italy we selected a sample of 100 municipalities (of 2273 signatories) to cover systematically cities of different size, geographic location and duration of CoM membership. The breakdown of interviews conducted in each country is: Italy (6), Germany (4), Poland 2 and the UK (5). Our interviewees represent a balanced sample of small and large cities from each country, covering cities with more (e.g., Glasgow or Padua) or less (e.g., Borough of Poole or Palermo) advanced climate strategies.

The interview schedules aimed at unpacking the specific learning effects enabled by the CoM instruments, including (1) the relevance and usefulness of CoM templates and related methodological guidance for improving local knowledge on sustainable energy policies and instruments; (2) the degree to which the CoM signatories have actually deployed and viewed CoM training and benchmarking tools as helpful; (3) the way in which CoM participation has affected local organizational reforms and changed their external partnerships. The natural bias of this inquiry reflects the fact that the more 'proactive' cities also agreed to interviews.

The next paragraphs present a detailed analysis of the learning dynamics summarized in Table 1.

\section{Learning at the top: the Commission and the EU level coordinating and supporting bodies}

The EU Commission has shown signs of a broad policy learning process related to the CoM. First, it has progressively upgraded the program's objectives and targets, reflecting the changing international commitments deriving from the Paris Agreement and taking stock from the implementation experience. In 2015, CoM moved from the original 20/20/20 EU Climate and Energy Package goals to a more ambitious adaptation framework, establishing the EU 40\% GHG-reduction target by 2030 and setting out new political proprieties for resilient cities with access to sustainable, secure and affordable energy (CoM 2018). Subsequently, drawing on the CoM's overall success in activating local commitment to EU climate objectives, the Commission further revised the CoM objectives: promoting the commitment to the EU 2050 Roadmap and specifying CoM's contribution to the three thematic strategies, namely 'Clean Energy for all Europeans' Package, the 'Europe on the Move' Clean Mobility Package and EU adaptation strategy. More recently, the Commission has explicated the linkage between the CoM actions and the European Green Deal and a European Climate Pact presented in 2019; it considered all three to be mutually reinforcing for a cross-sector approach, promoting 'clean buildings', building renovations, sustainable transport and smart mobility.

This political priority shift has paralleled the consolidation of the CoM strategic partnership globally. In 2016, the EU Commission initiated the CoM merging with the Compact of Mayors, thereby forming the Global Covenant of Mayors for Climate and Energy, the largest climate movement of local governments. This move, along with establishing the CoM political board composed of seven mayors and elected representatives, aimed to strengthen the program's political uptake both at the international and EU levels, as 
political support has proved crucial for the CoM success since its establishment (van der Veen et al., 2013).

Lastly, the EU Commission has commissioned various evaluations and thematic studies to assess the quality of the CoM performance, identify barriers to effective implementation, evaluate the signatory satisfaction with program activities and specific policy tools, and understand its overall relevance for enhancing local climate commitment across EU countries (van der Veen et al., 2013; CoM, 2017; JRC 2017). These instruments have contributed to developing the CoM's own monitoring processes, although they do not constitute a fully fledged single-loop learning.

A specific instrument learning dimension is clearly discernible within the overall assessment exercise, driven by the objective to enhance the program's effectiveness, diffusion and accessibility across EU countries. Drawing on the lessons learnt and shortcomings identified in the assessment documents, the CoM's managing bodies have revised templates and methodological guidance, published additional thematic tutorials and organized thematic webinars to provide the signatories with more fine-tuned assistance on various substantive and procedural matters (CoM, 2019). This more strongly suggests a single-loop learning process.

Further evidence of top-level instrumental learning reflects CoM efforts to facilitate policy adjustments among its signatories from non-EU countries. Considering the aforementioned drawbacks experienced in EU countries, the CoM coordinating bodies have prepared a dedicated package of documents, including supplementary tools for developing emissions inventories, implementation measures and monitoring instruments. This effort encourages non-EU local authorities to join and helps them design and implement the required CoM activities. The Commission has launched ad hoc projects, including the Covenant of Mayors Office EAST project (Energy Cities, 2016) targeting Eastern Partnership and Central Asian countries from 2011 to 2015. The EAST project responded to CoM's previous implementation difficulties in EU countries due to linguistic problems (i.e., many EU municipalities do not widely speak English, the CoM's main working language) and the lack of the required expertise for drafting key CoM documents. The EAST project developed specific manuals and guidance translated into Russian and Ukrainian and promoted several capacity-building events. To complement this, the JRC committed further operational support in English and Russian to address signatories' technical questions (Energy Cities, 2016).

The organizational learning at the top mainly has revolved around the CoMO's (responsible for program coordination and implementation) activities. These activities include: support to signatories, promotion and communication, and the dissemination (with the JRC's cooperation) of the initiative's impact. Several characteristics enabling learning processes have underpinned the CoMO setup and functioning.

The CoMO activities are ensured through service contracts awarded for a four-year period to a consortium consisting of the largest European TMNs (transnational municipal networks). This arrangement allows for political support and program visibility at the largest possible scale, while simultaneously providing warranties for appropriate expert assistance to CoM signatories. Since 1990, TMNs have led the cities' climate change movement, improving information sharing, learning and implementation of local climate policies worldwide (Bulkeley \& Newell, 2015).

The CoMO consortium's composition only slightly changed from the 2013-2017 to the 2017-2021 period by including ICLEI Europe into the previously consolidated partnership composed of Energy Cities, Climate Alliance, the Council of European Municipalities and Regions (CEMR), EUROCITIES and FEDARENE. Notably, these 
TMNs' secretariats possess long-standing experience and specific knowledge in the sustainable energy and climate fields; each secretariat contributes to a sizeable pool of knowledge resources at the top by putting one or two staff at the CoMO's disposal. The fact that these officers normally divide their time between the CoM-related and their host organization's activities ensures the TMN circulation of policy-relevant knowledge.

The CoMO staff perceives the consortium composition's continuity as particularly important because it ensures the consolidation of a massive pool of valuable expertise and practical knowledge about the CoM implementation progress and problems located in CoM member countries (Interview 18). However, the CoMO remains substantially understaffed (relying on approximately 12 full-time equivalence officers), which limits operational capacity and signatory support. Moreover, due to the absence of dedicated staff in the EU Commission, there is a risk that the Commission (except for the JRC) will not fully internalize the CoMO's accumulated knowledge, which then remains dispersed across the different TMN secretariats. In contrast, the JRC has generated valuable specialized knowledge on climate policies for local level diffusion through the $\mathrm{CoM}$ and has contributed consistently to strengthening the program monitoring and evaluation.

The EU Commission has activated additional human and organizational resources (through dedicated service contracts, projects and regional offices) to support the CoM activities beyond EU borders. In the previously mentioned EAST project, the consortium consisted of Energy Cities, Climate Alliance, the Regional Environmental Center for Central Asia (CAREC) and the Ministry of Economic Affairs of Netherlands. DG DEVCO (International Cooperation and Development) and DG NEAR (European Neighborhood Policy and Enlargement Negotiations) acted as contracting authority for the EU. Several learning-enabling tools underpinned the EAST project governance, aimed at promoting knowledge diffusion about the CoM-related activities through enhanced socialization and coordination. For example, the contractors (consortium project director, key experts and WP leaders), the contracting authority and representatives of different stakeholders, including the JRC, jointly organized steering committee meetings. The CoM Office East has regularly interacted with several target actors that benefitted from the project activities (signatory cities, national or territorial coordinators, supporters), established a regular collaboration with other EU projects and cooperated with many local stakeholders that could promote the CoM activities (Energy Cities, 2016). This collaboration has ensured an expansive involvement in the co-production of decisions and their implementation monitoring, thereby enabling the tailoring of CoM instruments to specific local needs.

The analysis above reveals CoM's substantial potential concerning the three types of learning at the top, but learning processes appear incomplete and somewhat unintentional. The evaluation activities' lack of a systematic and long-term perspective has hampered policy learning. One of the main weaknesses in instrument learning has been the CoM website, intended as the main learning-enabling device. The website data have often been partial and sometimes incoherent. After its 2018 restructuring, the website layout does not allow for simultaneous tracing of all the local indicators, such as monitoring progress and the delivery of benchmarks. This undermines effective oversight of the CoM signatories' overall progress. Lastly, as the COMO's staff has largely remained shared with their TMNs, institutionalization of expertise remains incomplete, hindering the CoM learning potential. Such failings affect the CoM's coherence and congruence (Howlett \& Rayner, 2013). 


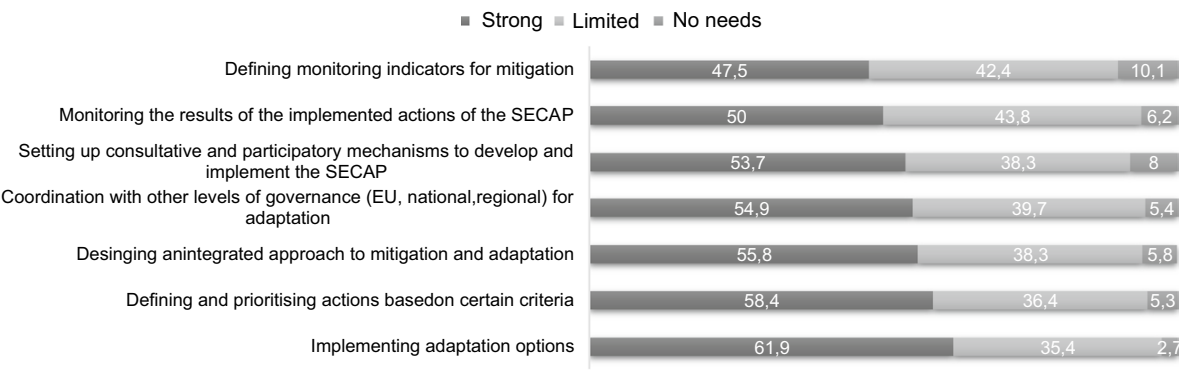

Fig. 1 Municipalities' knowledge needs: methodologies for climate planning. Source: CoM (2017)

\section{Learning from the top}

The learning dynamics 'from the top' have been likewise highly variable. As regards policy learning, the CoM agenda has attracted an impressively high following from the EU and beyond. Most of the local authorities who joined the program have significantly upgraded their climate policy agendas, not possessing local sustainable energy and climate strategies beforehand. Our interviews explain that the CoM's learning impact has been higher in the countries where domestic climate policies were missing (Interviews 13, 15, 16, 17). When mixed with advanced domestic local climate agendas, the CoM has mostly served to legitimize previous policies or strengthen individual components.

In addition to recognizing the CoM contribution to increasing local authority awareness, CoM signatories have valued its support for improving local knowledge and capacities in the sustainable energy and climate fields (van der Veen et al., 2013 ${ }^{1}$ ). More recent data show that climate change mitigation and adaptation awareness among CoM signatories has been relatively high; around $87.5 \%$ of respondents $(\mathrm{N}=593)$ claim to know what climate change mitigation and adaptation mean in policy terms (CoM, 2017). Nevertheless, as Fig. 1 illustrates, the demand for expert climate policy knowledge among the CoM signatories still appears high, particularly concerning adaptation strategies and specific policy instruments. In this sense, local authorities' learning needs cut across substantial and procedural aspects, and entail the challenge of developing evidence-based policies and designing an integrated approach to mitigation and adaptation, based on coordinated and participatory processes.

Our interviews also confirm that the degree of policy learning has varied considerably across and within countries; the CoM policy guidance is much more appreciated in countries, such as Italy or Poland, that lack consolidated domestic policies on energy and climate at the local level (Interviews 1, 2, 6, 11). In these countries, the instrumental learning has been particularly relevant, as the CoM methodologies have supported both the preparation of local SEAPs and the overall re-definition of local policy agendas toward better environmental sustainability and climate objectives.

A Warsaw municipal officer explained:

\footnotetext{
${ }^{1}$ The survey collected 593 replies (514 from municipalities) — 491 of which were CoM signatories. Most municipalities represented (67.3\%) have less than 50,000 inhabitants. $32.1 \%$ have less than 10,$000 ; 35.2 \%$ have 10,000-50,000. Italy and Spain had the highest number of responses, reflecting the share of CoM signatories.
} 
"The CoM gives us the goals and the measures of how to control the process[...], the possibility to make comparison to the other administrations, and [...] make better understand how we can change in many fields, including climate, transport infrastructures, and water management" (Interview 17).

Other interviewees made similar arguments (e.g., Interview 14), while German and UK public servants expressed a very different view; these officials unanimously stressed that they had developed their instruments for climate and sustainable energy policies before joining the CoM, based on the nationwide programs and networks. However, our UK interviewees highlighted CoM's useful insights for upgrading their local strategies and instruments, particularly by enabling the creation of collaborative projects developed around the CoM-related activities and financed by EU funds (Interviews 5, 7, 8). One UK interviewee observed:

"Initially we saw the CoM potential for support on reduction targets, but then we realized it was important for being pro-active in EU networks and for upgrading our own policy agenda [...]. We want also to be able to benefit from the discussion with our peer cities [...]" (Interview 7).

According to German municipalities, CoM participation helped them increase international visibility and strengthened cooperative linkages with other leading cities, while also consolidating their local climate agendas independent of the national political priorities (Interviews 3, 6).

Overall, the demand for policy and instrumental learning that the CoM can potentially satisfy remains high. The CoM survey $(\mathrm{N}=593$ replies; see $\mathrm{COM}, 2017)$ found that roughly $78.2 \%$ of municipalities have developed a mitigation plan and only $29.2 \%$ had an adaptation plan by 2017. Considering that the CoM has committed to the adaptation agenda since 2015 after focusing exclusively on mitigation policies and instruments, it now must consolidate this relatively new pillar of adaptation activities and push policy and instrument learning.

A strong cross-country variation in municipalities' priorities shows that domestic contexts determine the signatories' learning demands. For example, 30\% of signatories in France have expressed the need for assistance to develop mitigation policies as opposed to $70 \%$ for adaptation measures; the figures in Italy were $40.3 \%$ for adaptation policies and $34.2 \%$ for mitigation policies. This confirms that local authorities still view mitigation policies and instruments (SEAPs) as having primary importance, although the motivation to upgrade their status by drawing adaptation strategies (SECAPs) also has increased.

The JRC's guidance has largely driven the instrumental learning process; it covers the various steps in the $\mathrm{SE}(\mathrm{C}) \mathrm{AP}$ cycle, from the creation of Basic Emission Inventories (BEIs), to the preparation of plans and their implementation/monitoring. The CoMO has created a sizeable virtual library to develop and diffuse policy-relevant mitigation/adaptation knowledge. The CoMO has promoted numerous training and information events, aiming to increase local climate expertise. Lastly, the CoM website now features an interactive funding guide (https://www.eumayors.eu/support/funding.html); it provides a comprehensive overview of EU financial instruments that may support the CoM-related activities, including best-case examples and lessons learnt.

The CoM signatories have widely appreciated both the JRC's technical guidance and assistance, even if the learning needs and the signatories' perception about the actual CoM participation benefits varied significantly across and within countries. As Fig. 2 illustrates, a few years after the CoM launch the possibility of obtaining specialized 


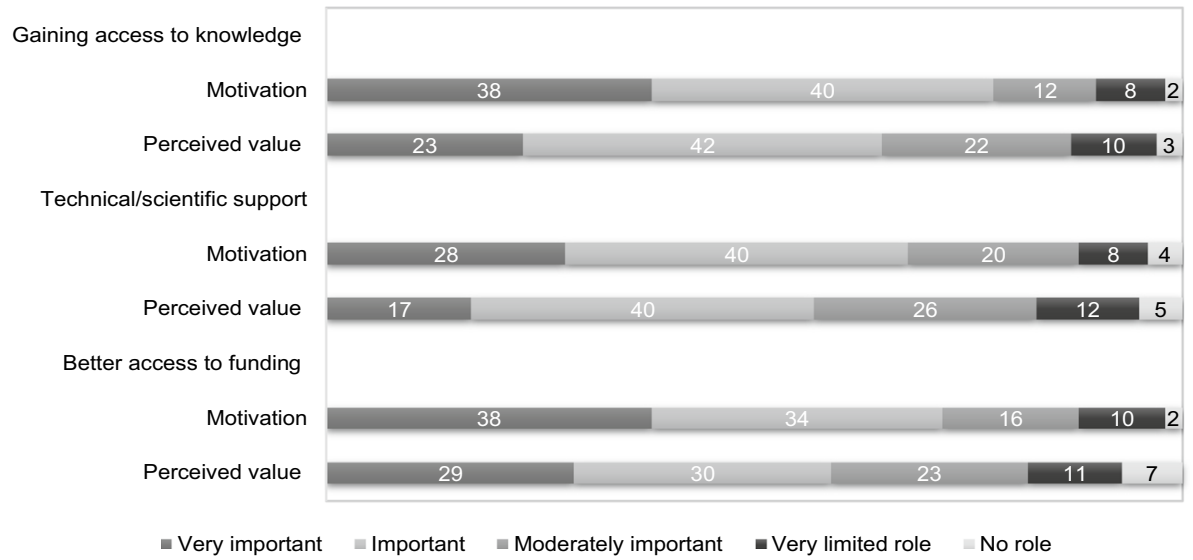

Fig. 2 The motivation to join CoM and perceived participation benefits. Source: Authors' elaboration on data collected by van der Veen et al. (2013)

knowledge has been the most frequently mentioned motivation for joining CoM and its major perceived benefit. 78\% of the CoM survey (van der Veen, 2013) respondents declared having used and appreciated the program Guide Book. Only $40 \%$ were involved in direct interactions with the JRC; $45 \%$ used the CoMO's technical support to prepare their SEAPs. By contrast, around $70 \%$ of respondents have obtained support from the respective territorial coordinators; $55 \%$ have used the CoM e-learning tools, and almost 50\% have interacted with a peer municipality (van der Veen et al., 2013). Overall, signatories' expectations appear to have been satisfied, although Fig. 2 reveals variation concerning the three main participation rationales.

Our interviews explain that the CoM methodological and technical guidance mainly have been deployed actively in those countries where domestic guidance and support for developing local energy and climate planning were missing or inadequate, such as Italy and Poland. In the countries where similar domestic policy programs were available, the implementation of CoM instruments has often been perceived as an additional workload rather than a valuable learning source. For example, German public officers charged with the CoM activities (Interviews 3, 6, 9, 11) note the duplication of previous work (required for national energy planning initiatives) preparing their planning and monitoring documents. The changes required to adjust local instruments to the CoM format were costly and largely unnecessary (Interviews 6, 9). By contrast, our UK interviewees acknowledged the complementarity between the CoM and their ordinary planning documents and the related domestic monitoring commitments.

Among the barriers to instrumental learning, local authorities have stressed the lack of staff and resources. "I think that the human resources in local governments are quite restricted [...]; it is also a question of language skills" (Interview 3). A lack of capacities has been particularly significant in the countries where previous domestic instruments did not exist. One Polish interviewee stated:

"We have been provided with a lot of tools [...], but some instruments [monitoring, benchmarking] could be more user friendly [...]. Many aspects have never been touched before" (Interview 16). 


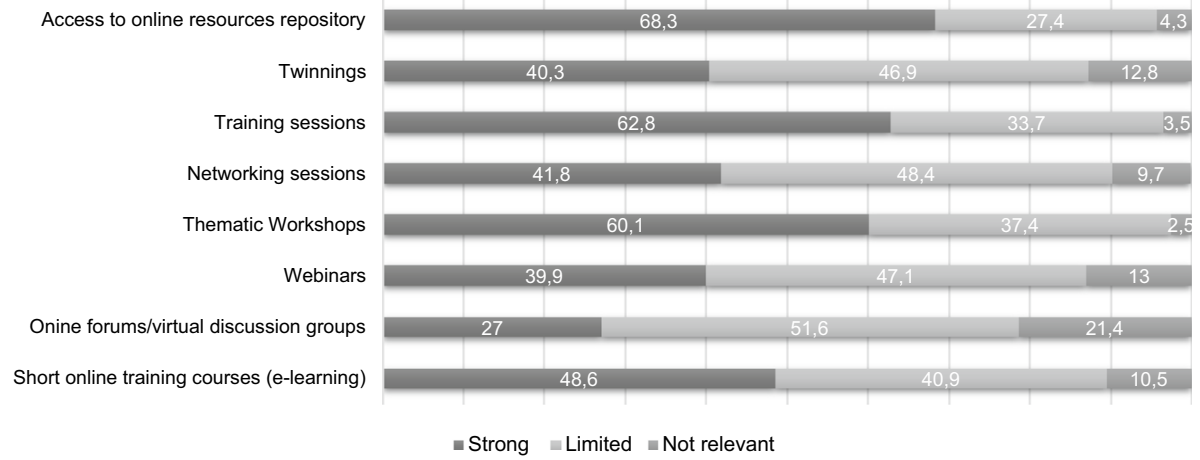

Fig. 3 The perceived relevance of the CoM capacity and learning building activities. Source: Authors' elaboration on CoM (2017) data

Likewise, Italian municipalities perceived the $\mathrm{CoM}$ as an opportunity to build municipal sustainable development agenda and instruments, although the gap to recover was huge with very limited resources available. One interviewee stated:

"We have faced huge problems when preparing the CoM-related documents [...]; there was no data on energy consumption at the local level, no software for collecting such data, no methodology. And we had really limited knowledge on how to perform these tasks" (Interview 14).

Often external experts were hired to develop the local policy documents, and consequently the policy and instrumental learning for municipalities was limited or non-existent (Interview 12).

Overall, signatories' perceptions of the CoM instruments intended to promote learning and capacity building have been positive (CoM, 2017). As Fig. 3 shows, signatories consider the access to online resource repositories (Guidelines, Tools, Studies, etc.) and the CoM expert-led training sessions as highly important $(68.3 \%$ and $62.8 \%$ of respondents, respectively). Thematic workshops primarily aimed at the exchange of good practices between peers were very important to $60 \%$ of respondents, whereas only $48.6 \%$ viewed the short online training courses (e-learning tools) as useful.

However, insufficient English language knowledge has often figured as a major barrier to using CoM policy learning instruments: 57\% in Poland, $40 \%$ in Belgium, France and Germany; $30 \%$ in Italy and Spain have indicated that they would not participate in the CoM learning activities in English (CoM 2016).

Implementing CoM has entailed changes in the local administrations' structures and their policymaking styles. To implement the CoM-related activities, signatories often have made organizational adjustments, including establishing new units and ensuring internal coordination between the different municipal departments concerned. They also had to establish procedures to involve citizens and social and economic stakeholders in the definition and implementation of local plans. Both these aspects were new for many signatories. As one Polish interviewee emphasized, CoM participation required a comprehensive reorganization of local administration offices and functions:

"[...] we collected all the projects in our organization to achieve the SEAP goals, structured our department [...] and coordinated it with other offices. We also estab- 
lished a climate protection committee to help the CoM activities and [...] invited NGOs to collaborate with it" (Interview 17).

In the UK, wider partnerships have developed around the process of implementing SEAPs. "Originally we had Climate Change Strategy group which was multi-stakeholders voluntary private sector organization but then we involved the university. We set up a City Climate commission advising on how the city can achieve the carbon reduction targets" (Interview 10).

Broader assessments (van der Veen et al., 2013) have also highlighted that creating cross-sectoral coordination structures and procedures related to the SEAPs activities has been one of the most relevant changes prompted by CoM participation. Although interviewees from all our country samples have emphasized the difficulties with implementing these changes, they have valued highly the newly created synergies for effective administrative performance. Moreover, authorities have established external partnerships that engage private actors and local communities, thereby increasing citizen awareness about the relevance of climate policies and particularly about the CoM. They also leverage private investments in the energy efficiency and sustainable energy production activities included in local plans. These characteristics differed substantially from more traditional energy policies that neither required coordination within the local administration nor necessitated collaborative networks with private companies and local communities.

\section{Learning from below}

The CoM has created a range of bottom-up instruments to enable interactions and exchange knowledge. The CoM introduced the mandatory benchmarking tool, to encourage municipalities to identify and share with the CoM community locally generated good practice. The CoM created an online database containing achievements, case studies and city profiles to offer members useful tips for developing and improving local energy and climate interventions. Both instruments have promoted policy and instrument learning.

A network of territorial coordinators and supporters was established, involving upperscale territorial entities (Regions and Provinces) and specialized energy and climate agencies. The network's objective has been to deploy regional and provincial potential (i.e., fundamental legal and financial knowledge and resources) to facilitate local level policy change. This architecture has helped activate a wide-scale bottom-up knowledge diffusion process, providing the CoM signatories with valuable support for all learning types. Beyond contributing to increasing CoM visibility among local authorities, territorial partnerships have supported local learning by enabling technical and methodological assistance to municipalities, helping municipalities to adapt the CoM methodology to local circumstances and facilitating the elaboration of SEAPs and accompanying documents (Bertoldi et al., 2010).

This mechanism has also included a package of actions for enhancing local energy and climate capacities (Melica et al. 2018). For example, some coordinators have handled the data collection and analysis for BEIs and assisted local authorities in identifying possible actions and resources to include in SEAPs; others have assumed the responsibility for drafting the climate action plan on behalf of their signatories or performed a preliminary assessment of local SEAPs under their coordination. The latter was typically performed by provinces that have directly financed the drafting of SEAPs and set some minimum requirements (either consistent with the analysis criteria applied by JRC or even more stringent) for municipalities to receive the contribution. Considering similarities between 
SEAPs presented under the same territorial coordinator, the JRC proposed adopting a "grouped approach" to their assessment (Covenant of Mayors Office 2014; Melica et al. 2018). This involved presenting a detailed description of the methodology followed for all the SEAPs along with a representative sample of SEAPs for analysis, entailing policy, instrumental and organizational learning.

The highest share of grouped SEAPs has been registered in Spain (98\%), Belgium and Italy (respectively, with $93 \%$ and $70 \%$ of signatories under a territorial coordinator), where there is a high concentration of small (less than 50,000 inhabitants) and very small municipalities (less than 10,000 inhabitants). In these countries, the intermediate bodies' support has been fundamental for the CoM signatories to develop climate policy knowledge and capacities, since they lacked national instruments for local energy planning. For example, the Province of Barcelona has provided guidance to municipalities in identifying the most appropriate actions to reach their targets. For each action a detailed fiche was prepared, which comprises - besides the estimation of cost, energy savings, carbon dioxide reduction targets and responsible body-other fields potentially useful in the implementation and monitoring phase such as categories of the actions, priorities, progress indicators and linkage with other planned actions or with other existing municipal plans (Melica et al. 2018). Many local actors agree that the CoM has triggered increased interaction and cooperation concerning climate polices among the local and intermediate government tiers (van der Veen et al., 2013).

The aforementioned activities have contributed likewise to regional level policy learning; regional governments have become more aware about the local potential for achieving climate objectives and developing more comprehensive strategies for enhancing this potential. One of the most relevant developments has been the regions' financial support for the CoM-related activities, particularly through the European Regional Development Fund (ERDF). The regional governments' political commitment has been crucial for creating opportunities for local authorities to invest in developing specific policy capacities and increasing sustainable energy investments (CoM, 2017). For example, the Italian Abruzzo Region has combined policy and financial support for the Covenant signatories, designing a specific priority Axis II "Energy sustainability" in its 2007-2013 ERDF Operational Program and investing 35 million euros into Covenant-related activities. Utilizing experience of the past CoM coordination activities, the region also established a management body (Cabina di Regia) involving the four provinces and the National Association of Italian municipalities to support CoM implementation: 305 SEAPs (i.e., all of the territory's municipalities) were developed either by the provinces directly or with their energy agencies' support.

Likewise, the Covenant supporters that include not-for-profit organizations (i.e., associations of local and regional authorities, networks, and local and regional energy agencies) have contributed widely to facilitating learning among the CoM signatories by deploying their networks and expertise in a number of crucial CoM areas (i.e., energy, climate change). Their support has been particularly important for organizational and policy learning, as they have intensified cooperation between local authorities, media, local communities, and stakeholders and organized numerous bilateral and multilateral meetings at regional/national level to encourage financial and political support for CoM activities (CoM, 2016). They have also promoted cooperation between the signatories and the scientific community, helping adapt the CoM guidance to their specific legislative, regulatory and financial contexts.

These dynamics show that the CoM's learning potential has extended beyond the originally envisaged scope and a wider spillover effect covering the policy, organizational and 
relational dimensions has occurred, involving not only the Covenant signatories but also other territorial actors. The synergies between the local and intermediate territorial governments, which have developed around the CoM-related activities over time, have been mentioned as one of the CoM's most important beneficial effects (van der Veen et al., 2013). This is the CoM's broader learning effect.

The possibility to organize information and training events (conferences, webinars, etc.) has also been a valuable instrument for encouraging signatory capacity building. Importantly, the CoMO has been pro-active in promoting these activities; the CoM signatories have launched individual and collective initiatives on a variety of relevant topics. The CoMO has regularly provided information on EU funding opportunities to facilitate the creation of transnational partnerships and encourage scaling up of successful local experiences through joint projects.

In addition to expressing their appreciation of these activities, most interviewees stated that they had expanded their international partnerships and developed new collaborative projects thanks to their CoM participation, thereby intensifying exchanges and borrowing from others' experiences. One Warsaw interviewee stated:

"I participated in the Asian partnership and met local administrations from the former Soviet Union republics to explain to them why it was important to take part in the CoM initiatives [...]. I think that we could do more in the Eastern part of Europe".

Importantly, experienced signatories with advanced climate policies have also appreciated these opportunities. For example, the city of Glasgow developed its Energy and Carbon Masterplan aided by an EU FPVII funded project (Interview 7). Many other cities' consortia, including those interviewed for this research, obtained EU Horizon 2020 funding for improving their climate strategies based on joint innovative approaches and methodologies.

\section{Conclusions}

Our findings (Table 2 summarizes the evidence for learning) contribute to improving our understanding of policy learning dynamics in several ways. First, concerning the question about how an instrument mix may affect wider policy and instruments contexts (Howlett \& Rayner, 2013), our analysis shows that one instrument mix can generate more than one learning type, and that learning processes can develop across multiple directions and scales. Likewise, evidence also indicates that learning dynamics can develop at varying intensities and speeds, and that force-free dynamics can actually drive learning processes and even be unintentional. Both of these findings are consistent with the propositions of reflexive learning scholarship (Dunlop \& Radaelli, 2013, 2018), which also suggests that the availability of learning instruments does not constitute the sufficient condition for learning to occur. As our analysis confirms, an overlap of similar instruments existing at supranational and domestic arenas may create tensions with learning processes developing across the different types and levels.

Concerning learning at the top, actors have gathered considerable lessons about how to increase the program's viability and improve its impact, although our analysis has revealed substantial shortcomings. The CoM has gradually expanded its policy agenda, invested in a stronger political profile and enabled the pooling of the policy knowledge encompassed 


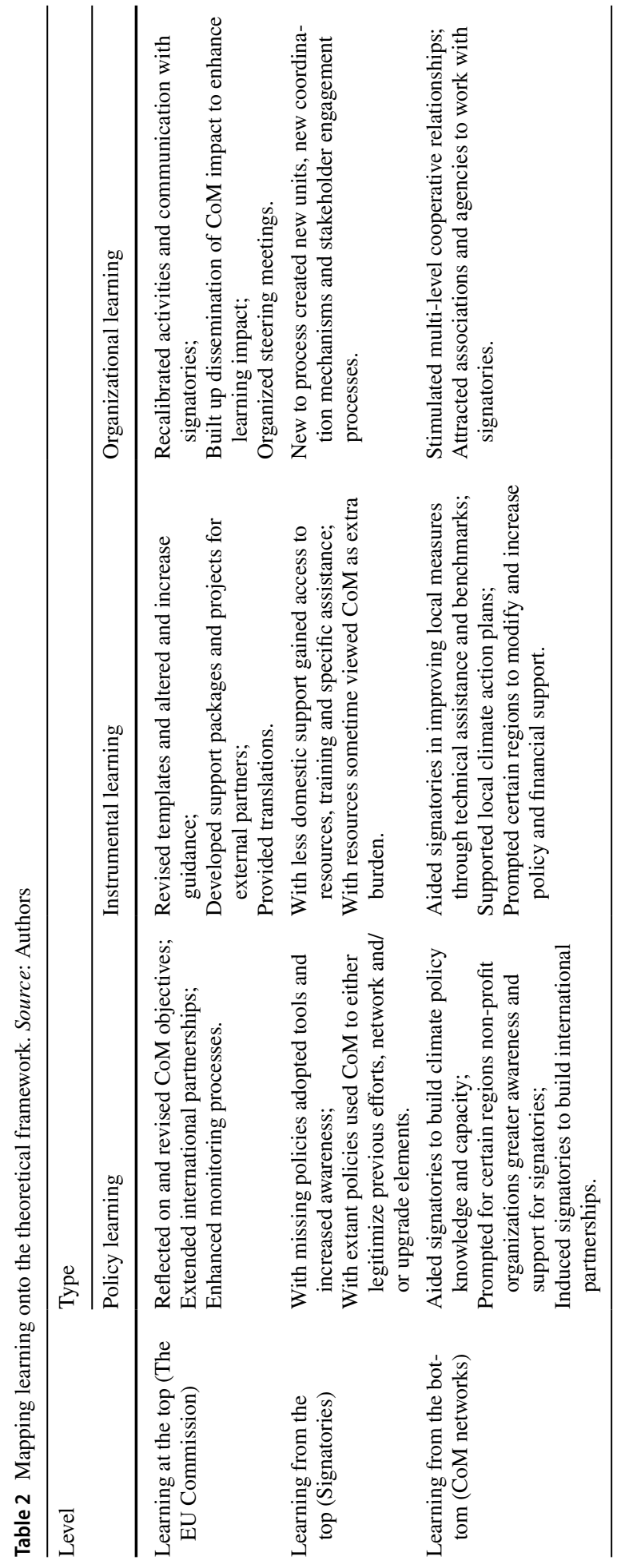


by the CoMO and the JRC technical expertise. Program objectives and targets have been upgraded progressively to reflect the evolving international climate commitments, while simultaneously reflecting upon the implementation experience. However, a systematic and comprehensive evaluation of the CoM implementation has been lacking, with only a few assessments of CoM performance.

In line with our expectations, the provision of monitoring and assessment mechanisms within CoM processes and the creation of conditions where CoM actors can increase the rate of interactions and engagements with networks of actors inside and outside the CoM, suggest that the CoM mix has enhanced the three learning types. Nevertheless, the reflection processes have not been sufficiently systematic to more than partly meet Propositions One and Three. In terms of the top-level dynamics, the CoM mix also appears to have flexibility to adjust to iterations in thinking, reflection and ambition. Although these fulfill elements of Proposition Two, there remains a fundamental resourcing question; one dynamic that has played a role but not been featured in our framework conditions goes beyond resource support to encompass more fully how expertise and knowledge are institutionalized and continuity maintained.

The learning dynamics from the top also have varied significantly: the degree to which CoM signatories have deployed the CoM policy instruments, adopted the related methodologies and introduced organizational changes have differed substantially between and within countries. Although both our findings and larger inquiries (van der Veen et al., 2013) have confirmed the CoM's importance as a source of specific knowledge and methodologies, its learning effect has been higher in the countries where the program has filled the gap in the domestic local sustainable energy and climate policies, and where territorial coordinators offered substantial support. By contrast, the CoM relevance was marginal or null in countries where similar domestic programs existed previously. In those contexts, the learning effect has occurred almost exclusively within the political dimension, mainly involving the ambition to increase the international visibility and partnerships.

This evidence echoes the findings of previous studies examining subnational level learning dynamics (Benz \& Fürst, 2002), suggesting also that Proposition One needs an additional set of conditions, namely that a policy mix tends to have a strong learning impact when placed in a context where there it is less likely to clash with extant measures. For those CoM signatories with a significant pre-existing policy instrument mix, this additional layering did not create a substantial range of new resources and learning (beyond legitimation, positioning and networking). Instead, the CoM mix created burdens, if not outright conflicts, with the extant policy array, suggesting that conditions for Proposition Two had not been met in the UK and Germany members we investigated.

The CoM bottom-up learning dynamics have also developed unevenly. Signatories on the smaller municipal scale have benefitted more, particularly when supported by proactive, engaged regional bodies and technical support (as Proposition One predicts). That dynamic was less prevalent in larger authorities with more resources and instruments in place, with the danger of the CoM efforts competing for limited time. Where municipalities lacked previous resource, the benchmarking database and network support contained in the CoM mix generated learning, interestingly both at the local and the provincial/regional level.

In summary, although the potential of all learning resources and instruments activated by the CoM requires more exploration, our evidence indicates that the CoM policy mix appears to be sufficiently coherent. The program has established a set of potentially complementary instruments aimed at enhancing learning among different actors (i.e., templates, guidelines, training, etc.). By contrast, the congruence of this design 
seems somewhat problematic; many of these instruments are not necessarily working in the same direction, since the connections between the instruments are open-ended and depend on the program signatories' individual choices. Differing incentives and choices as to how to implement the CoM policy mix, which necessarily relies on voluntary and reflective action, lead the CoM to have substantially differing impact across and beyond the EU.

Our original analytical approach has allowed to us trace a comprehensive picture of how the different learning types occur within and across the different levels. The study has indicated some of the important conditions that require fulfillment for instruments and mixes of instruments to have a learning impact, thereby adding novel insights on whether and how the potential of EU learning opportunities can be better deployed (Radaelli, 2008; Zito \& Schout, 2009). Nevertheless, the CoM mix, in the right conditions, suggests a flexible instrument design that can encourage learning efforts. Extending the empirical analysis to cover other countries with various regional characteristics and approaching less engaged municipalities would allow us to more fully generalize our findings and study barriers to learning.

Numerous research avenues promise further insights. More research at the microlevel would illuminate how the CoM's informational and networking dynamics interact with the other EU policy instruments promoting climate policy mitigation and adaptation. Another profitable research goal is assessing more closely the iterative reflection process and how specific actors evolve their thinking over time. The larger transnational dynamic of learning and networks that operate in the CoM could show how instruments work with global networks to communicate knowledge to face the climate emergency.

\section{Appendix: Interviews}

1. Bari Senior Energy Officer, July 2017

2. Bologna Senior Energy Officer, October 2016, July 2017

3. Bonn, Senior Officer, September 2017

4. Borough of Poole Senior Municipal Officer, June 2017

5. Durham Senior Municipal Officer, June 2017

6. Dusseldorf, Senior Energy Officer, September 2017

7. Glasgow Senior Energy Officer, June 2017

8. Glasgow Senior Economic Development Officer, November 2017

9. Heidelberg, Senior Energy Officer, September 2017

10. Leeds Senior Municipal Officer, June 2017

11. Munich, officer, September 2017

12. Padua, Senior Energy and Environment Officer, June 2016

13. Palermo, Senior Energy Officer, May 2017

14. Pesaro, Senior Energy and Environment Officer, May 2017

15. Venice Senior Officer, July 2017

16. Wroclaw, Senior Environment and Energy Officer, January 2018

17. Warsaw, Senior Environment and Energy Officer, January 2018

18. Covenant of Mayors Office, senior official, May 2018 
Funding Open access funding provided by Università degli Studi di Padova within the CRUI-CARE Agreement.

Open Access This article is licensed under a Creative Commons Attribution 4.0 International License, which permits use, sharing, adaptation, distribution and reproduction in any medium or format, as long as you give appropriate credit to the original author(s) and the source, provide a link to the Creative Commons licence, and indicate if changes were made. The images or other third party material in this article are included in the article's Creative Commons licence, unless indicated otherwise in a credit line to the material. If material is not included in the article's Creative Commons licence and your intended use is not permitted by statutory regulation or exceeds the permitted use, you will need to obtain permission directly from the copyright holder. To view a copy of this licence, visit http://creativecommons.org/licenses/by/4.0/.

\section{References}

Argyris, C. (1976). Single-loop and double-loop models in research on decision making. Administrative Science Quarterly, 21(3), 363-375.

Benz, A., \& Fürst, D. (2002). Policy learning in regional networks. European Urban and Regional Studies, 9(1), 21-35.

Bertoldi, P., Bornas Cayuela, D., Monni, S., \& de Raveschoot, R. (2010). Existing methodologies and tools for the development and implementation of sustainable energy action plans (SEAP). Available at: https://core.ac.uk/reader/38620420.

Bulkeley, H., \& Newell, P. (2015). Governing climate change. Routledge.

Energy Cities (2016). Support Services for the Covenant of Mayors East. Final report. Available at: http://www.soglasheniemerov.eu/IMG/pdf/COMO_East_2011-2015_report.pdf.

Collier, D. (2011). Understanding process tracing. Political Science and Politics, 44(4), 823-830.

CoM. (2016). Sustainable energy investment in European local authorities Report based on a survey by the Covenant of Mayors Office Covenant of Mayors Office. Available at: https://www.covenantof mayors.eu/IMG/pdf/WP2_Survey_report_final.pdf.

CoM (2017). Covenant community's needs for SE(C)AP design and implementation. CoM publication. Available at: https://www.eumayors.eu/support/library.html.

CoM. (2018). Open letter to European Energy Ministers to revise the Energy Union Governance Regulation incorporating the needs of local and regional governments. Available at: https://www.eumay ors.eu/support/library.html.

CoM. (2019). Annual Report 2019. Available at: https://www.eumayors.eu/support/library.html.

Covenant of Mayors Office. (2014). Covenant Territorial Coordinators: Crucial contributors to the Covenant of Mayors success. Available from https://www.covenantofmayors.eu/IMG/pdf/2015-08-CTC-rapportfinal.pdf.

Dunlop, C. (2015). Organizational political capacity as learning. Policy and Society, 34(3-4), 259-270.

Dunlop, C., \& Radaelli, C. (2013). Systematising policy learning: From monolith to dimensions. Political Studies, 61, 599-619.

Dunlop, C., \& Radaelli, C. (2018). The lessons from policy learning: Types, triggers, hindrances and pathologies. Policy and Politics, 46(2), 255-272.

Dunlop, C., \& Radaelli, C. (2019). Policy instruments, policy learning and politics: Impact assessment in the European Union. In G. Capano, M. Howlett, M. Ramesh, \& A. Virani (Eds.), Making policies work: First- and second-order mechanisms in policy design (pp. 115-136). Edward Elgar.

Gerring, J. (2017). Qualitative methods. Annual Review of Political Science, 20, 15-36.

Heclo, H. (1974). Modern social politics in Britain and Sweden: From relief to income maintenance. Yale University Press.

Hildén, M. (2011). The evolution of climate policies-the role of learning and evaluations. Journal of Cleaner Production, 19(16), 1798-1811.

Howlett, M., \& Cashore, B. (2009). The dependent variable problem in the study of policy change: Understanding policy change as a methodological problem. Journal of Comparative Policy Analysis, 11(1), 33-46.

Howlett, M., \& Rayner, J. (2007). Design principles for policy mixes: Cohesion and coherence in 'new governance arrangements.' Policy and Society, 26(4), 1-18.

Howlett, M., \& Rayner, J. (2013). Patching vs packaging in policy formulation: Assessing policy portfolio design. Politics and Governance, 1(2), 170-182. 
Joint Research Centre (JRC). (2017). Covenant of Mayors in figures: 8-year assessment. Publications Office of the European Union.

Jordan, A., Huitema, D., Van Asselt, H., \& Forster, J. (2018). Governing climate change: Polycentricity in action? Cambridge University Press.

May, P. (1992). Policy learning and failure. Journal of Public Policy, 12(4), 331-354.

Melica, G. Bertoldi, P. Kona, A. Iancu, A., Rivas, S., \& Zancanella, P. (2018). Multilevel governance of sustainable energy policies: The role of regions and provinces to support the participation of small local authorities in the Covenant of Mayors. Sustainable Cities and Society, 39, 729-739.

Moyson, S., Scholten, P., \& Weible, C. (2017). Policy learning and policy change: Theorizing their relations from different perspectives. Policy and Society, 36(2), 161-177.

Radaelli, C. (2008). Europeanization, policy learning, and new modes of Governance. Journal of Comparative Policy Analysis, 10(3), 239-254.

Radaelli, C. (2020). Regulatory indicators in the european union and the organization for economic cooperation and development: Performance assessment, organizational processes, and learning. Public Policy and Administration, 35(3), 227-246.

Ranson, M., \& Stavins, R. (2016). Linkage of greenhouse gas emissions trading systems: Learning from experience. Climate Policy, 16(3), 284-300.

Sabel, C., \& Zeitlin, J. (2008). Learning from difference: The new architecture of experimentalist Governance in the EU. European Law Journal, 14(3), 271-327.

Sanderson, I. (2002). Evaluation, policy learning and evidence-based policy making. Public Administration, $80(1), 1-22$.

Schoenefeld, J., \& Jordan, A. (2019). Environmental policy evaluation in the EU: Between learning, accountability, and political opportunities? Environmental Politics, 28(2), 365-384.

Simon, H. (1961). Administrative Behavior (2nd ed.). Macmillan.

Smeds, E., \& Acuto, M. (2018). Networking cities after Paris: Weighing the ambition of urban climate change experimentation. Global Policy, 9(4), 549-559.

van der Veen, G., Eparvier, P., Hinojosa, C., Ploeg, M., van Til, J., Altmann, M., Benintendi, D., Maio, P., Michalski, J., \& Trucco, P. 2013. Mid-term evaluation of the Covenant of Mayors initiative. Available from https://www.technopolis-group.com/report/mid-term-evaluation-covenant-mayors-initiative/.

van Erp, J., et al. (2019a). Introduction: The concept of smart mixes for transboundary environmental harm. In J. van Erp, M. Faure, A. Nollkaemper, \& N. Philipsen (Eds.), Smart Mixes for Transboundary Environmental Harm (pp. 3-24). Cambridge University Press.

van Erp, J., et al. (2019b). Conclusion: Smart Mixes in Relation to Transboundary Environmental Harm. In J. van Erp, M. Faure, A. Nollkaemper, \& N. Philipsen (Eds.), Smart mixes for transboundary environmental harm (pp. 329-343). Cambridge University Press.

Wolfram, M., et al. (2019). Learning in urban climate governance: Concepts, key issues and challenges. Journal of Environmental Policy \& Planning, 21(1), 1-15.

Wurzel, R., Liefferink, D., \& Di Lullo, M. (2019). The European Council, the Council and the Member States: Changing environmental leadership dynamics in the European Union. Environmental Politics, 28(2), 248-270.

Zito, A., \& Schout, A. (2009). Learning theory reconsidered: EU integration theories and learning. Journal of European Public Policy, 16(8), 1103-1123.

Publisher's Note Springer Nature remains neutral with regard to jurisdictional claims in published maps and institutional affiliations. 